\title{
The Role of Nuclear Medicine in the Clinical Management of Benign Thyroid Disorders, Part 1: Hyperthyroidism
}

\author{
Giuliano Mariani ${ }^{1}$, Massimo Tonacchera ${ }^{2}$, Mariano Grosso ${ }^{3}$, Francesca Orsolini ${ }^{2}$, Paolo Vitti ${ }^{2}$, and H. William Strauss ${ }^{4}$ \\ ${ }^{1}$ Department of Translational Research and Advanced Technologies in Medicine and Surgery, Regional Center of Nuclear Medicine, \\ University of Pisa, Pisa, Italy; ${ }^{2}$ Endocrinology Unit, Department of Clinical and Experimental Medicine, University of Pisa, Pisa, \\ Italy; ${ }^{3}$ Regional Center of Nuclear Medicine, University Hospital of Pisa, Pisa, Italy; and ${ }^{4}$ Molecular Imaging and Therapy Service, \\ Memorial Sloan Kettering Cancer Center, New York, New York
}

Learning Objectives: On successful completion of this activity, participants should be able to (1) acquire knowledge on the clinical manifestations and
underlying pathophysiology of the different forms of hyperthyroidism; (2) understand how to interpret ultrasound imaging and radionuclide evaluation in patients with hyperthyroidism; and (3) become familiar with the different methodological approaches to radioiodine therapy in patients with hyperthyroidism.

Financial Disclosure: The authors of this article have indicated no relevant relationships that could be perceived as a real or apparent conflict of interest.

CME Credit: SNMMI is accredited by the Accreditation Council for Continuing Medical Education (ACCME) to sponsor continuing education for physicians. SNMMI designates each JNM continuing education article for a maximum of 2.0 AMA PRA Category 1 Credits. Physicians should claim only credit commensurate with the extent of their participation in the activity. For CE credit, SAM, and other credit types, participants can access this activity through the SNMMI website (http://www.snmmilearningcenter.org) through March 2023.

Benign thyroid disorders, especially hyper- and hypothyroidism, are the most prevalent endocrine disorders. The most common etiologies of hyperthyroidism are autoimmune hyperthyroidism (Graves disease, GD), toxic multinodular goiter (TMNG), and toxic thyroid adenoma (TA). Less common etiologies include destructive thyroiditis (e.g., amiodarone-induced thyroid dysfunction) and factitious hyperthyroidism. GD is caused by autoantibodies against the thyroid-stimulating hormone (TSH) receptor. TMNG and TA are caused by a somatic activating gain-of-function mutation. Typical laboratory findings in patients with hyperthyroidism are low TSH, elevated free-thyroxine and free-triiodothyronine levels, and TSH-receptor autoantibodies in patients with GD. Ultrasound imaging is used to determine the size and vascularity of the thyroid gland and the location, size, number, and characteristics of thyroid nodules. Combined with lab tests, these features constitute the first-line diagnostic approach to distinguishing different forms of hyperthyroidism. Thyroid scintigraphy with either radioiodine or $99 \mathrm{mTc}$-pertechnetate is useful to characterize different forms of hyperthyroidism and provides information for planning radioiodine therapy. There are specific scintigraphic patterns for GD, TMNG, TA, and destructive thyroiditis. Scintigraphy with ${ }^{99 m T c-}$ sestamibi allows differentiation of type 1 from type 2 amiodarone-induced hyperthyroidism. The radioiodine uptake test provides information for planning radioiodine therapy of hyperthyroidism. Hyperthyroidism can be treated with oral antithyroid drugs, surgical thyroidectomy, or ${ }^{131}$ Iiodide. Radioiodine therapy is generally considered after failure of treatment with antithyroid drugs, or when surgery is contraindicated or refused by the patient. In patients with TA or TMNG, the goal of radioiodine therapy is to achieve euthyroid status. In GD, the goal of radioiodine therapy is to induce hypothyroidism, a status that is readily treatable with oral thyroid hormone replacement therapy. Dosimetric estimates based on the thyroid volume to be treated and on radioiodine uptake should guide selection of the ${ }^{131}$ I-activity to be administered. Early side effects of radioiodine therapy (typically mild pain in the thyroid) can be handled by nonsteroidal antiinflammatory drugs. Delayed

Received May 26, 2020; revision accepted Sep. 2, 2020.

For correspondence contact: Giuliano Mariani, Regional Center of Nuclear Medicine, University of Pisa, Via Roma 57, I-56126 Pisa, Italy.

E-mail: giuliano.mariani@med.unipi.it

Published online Oct. 2, 2020.

COPYRIGHT @ 2021 by the Society of Nuclear Medicine and Molecular Imaging. side effects after radioiodine therapy for hyperthyroidism are hypothyroidism and a minimal risk of radiation-induced malignancies.

Key Words: hyperthyroidism; toxic multinodular goiter; toxic thyroid adenoma; destructive thyroiditis; amiodarone-induced thyroid dysfunction; autoimmunity

J Nucl Med 2021; 62:304-312

DOI: $10.2967 /$ jnumed.120.243170

$\mathbf{T}$ he thyroid is the largest endocrine gland in the body. Adequate levels of circulating thyroid hormones are crucial for proper function of virtually all tissues and organs in the body. Disorders of the thyroid gland are the most prevalent endocrine disorders (1). A metaanalysis of thyroid dysfunction in Europe between 1975 and 2012 (2) reported the prevalence of patients with overt hypothyroidism to be $3.05 \%$ and the prevalence of hyperthyroidism to be $0.75 \%$, with even higher estimates for undiagnosed hypothyroidism and hyperthyroidism (4.94\% and $1.72 \%$, respectively). This would translate into nearly $11 \%$ of the population affected by some form of thyroid dysfunction. By comparison, a survey in the United States reported a $1.2 \%$ prevalence $(0.5 \%$ overt and $0.7 \%$ subclinical) (3) of thyroid disease (4). The American Thyroid Association suggests that more than $12 \%$ of the United States population will develop a thyroid condition during their lifetime. The prevalence of thyroid disorders is even higher in selected populations, such as elderly $(5,6)$ or obese subjects (7).

This article will focus on the role of nuclear medicine in the clinical management of patients with benign thyroid disorders, which constitute most diseases affecting the thyroid gland. Less than $5 \%$ of all thyroid nodules are malignant, and thyroid cancer represents less than $1 \%$ of all cancers.

The discovery of iodine was the result of serendipity. From 1792 until 1815 there was almost uninterrupted war in Europe, with France as a major participant. To feed their war machine, the French required a continuous supply of gunpowder, which was 
made from a combination of sulfur (10\%), charcoal (15\%), and potassium nitrate $(75 \%)$. The French had depleted their supply of wood and were burning seaweed, both for charcoal and to recover potassium nitrate. Bernard Courtois and his father manufactured potassium nitrate. In 1811, while preparing a batch of potassium nitrate from seaweed, Courtois added too much sulfuric acid. The excess acid caused the production of a purple cloud, some of which condensed as iodine crystals on nearby cool metal objects. The excess acid probably oxidized the iodides in seaweed to form iodine, which sublimated and formed the violet vapor. To characterize the purple crystals, Courtois gave samples to the French chemist Joseph-Louis Gay-Lussac and to the British chemist Humphry Davy. Gay-Lussac proved that the crystals were a new element and named it iode from the Greek ioeides, meaning violet-colored. Davy anglicized the name iode, calling it iodin, which then became iodine.

A Swiss physician, Jean-François Coindet, had used burnt sponge and seaweed to treat goiter, assuming iodine to be the active ingredient in seaweed. In 1819, he tested tincture of iodine in patients with goiter and observed that he could reduce the size of goiter within a week. He published his results in 1820; 75 years later, in 1896, Baumann reported high concentrations of iodine in the thyroid gland (8).

\section{CLINICAL PRESENTATION OF HYPERTHYROIDISM}

In populations with an adequate iodine intake $(\sim 150 \mu \mathrm{g} / \mathrm{d}$ in adults), autoimmune hyperthyroidism (Graves disease [GD]) is the etiology of hyperthyroidism in about $80 \%$ of cases. In populations with iodine deficiency, toxic multinodular goiter (TMNG), a nonimmune condition, is the most common cause (9) of hyperthyroidism. About $5 \%$ of cases are due to toxic thyroid adenomas (TAs), also known as Plummer disease. All these disorders exhibit a clear female preponderance, with a female-to-male ratio of about 6:1. Other etiologies, such as factitious hyperthyroidism, or excessive pituitary production of thyroid-stimulating hormone (TSH) due to either a TSH-secreting adenoma ( $<1 \%$ of all pituitary adenomas) or pituitary resistance to thyroid hormones, are very rare $(10)$. The occurrence of GD and TA peaks in the fourth decade of life, and TMNG typically occurs between $30-60$ y of age.

Symptoms of overt hyperthyroidism include symmetric fine tremor, heat intolerance, sweating, weight loss (despite increased appetite), hyperkinesis, nervousness, inability to concentrate, increased metabolic rate, tachycardia, cardiac arrhythmias (extrasystole, atrial fibrillation), increased intestinal motility (hyperdefecation), proximal muscle weakness, oligo- or amenorrhea, emotional instability, and irritability. The actions of thyroid hormones on various tissues and organs are summarized in Table 1. Young patients tend to present with the classic symptoms described above, whereas patients older than $75 \mathrm{y}$ are more likely to present with subtle symptoms such as apathy, fatigue, mood disturbance, and shortness of breath. Objective findings, such as atrial fibrillation, congestive heart failure, and ischemic acute coronary syndrome, are also more frequent in older people.

Thyrotoxicosis due to GD occurs in $0.2 \%$ of pregnancies. However, there is a condition-gestational transient thyrotoxicosisthat is secondary to elevated human chorionic gonadotropin levels (which stimulate the TSH receptor [TSHR]) in early pregnancy (12-16 wk). Gestational transient thyrotoxicosis occurs in about $1 \%-3 \%$ of pregnancies and improves spontaneously in the second trimester. This condition is associated with hyperemesis gravidarum, weight loss, dehydration, and electrolyte disturbances and is not associated with goiter or ophthalmopathy. Other causes of thyrotoxicosis in pregnancy are very rare.
In GD, infiltrative orbitopathy and, occasionally, infiltrative dermopathy and acropachy can occur. Orbitopathy presents with irritation of the eyes, injection of the conjunctiva and eyelids, proptosis that may lead to lagophthalmos, corneal dryness, ulceration, infection, diplopia, and various degrees of optic neuropathy. Dermopathy occurs in less than $5 \%$ of patients with GD as hyperpigmented, nonpitting edema, generally of the skin of the legs. Patients with orbitopathy should be referred to an ophthalmologist with specific expertise in this condition for further evaluation.

Decreased bone mineral density occurs in subclinical and overt hyperthyroidism. In patients with large TMNGs, tracheal deviation, tracheal compression, or esophageal compression may occur, causing obstructive symptoms.

\section{PATHOPHYSIOLOGY OF HYPERTHYROIDISM}

Environmental factors such as dietary iodine (11), smoking (12), and emotional stress can precipitate GD in genetically predisposed individuals who harbor multiple susceptibility alleles (in particular at the MHC, CTLA4, and PTPN22 loci) (13). As an organ-specific autoimmune disease, GD is caused by circulating autoantibodies (generally of the $\mathrm{IgG}_{1}$ isotype) directed against TSHR. In most patients, TSHR autoantibodies (TRAb) stimulate the thyroid after binding to TSHR, by increasing the production of intracellular cyclic adenosine monophosphate. TRAbs also interact with IGF1 receptors on the surface of thyroid cells and of orbital fibroblasts. The antibody-receptor complex promotes activation of intracellular cyclic adenosine monophosphate, with ensuing thyrocyte hyperplasia (causing gland enlargement), increased vascularity, and increased thyroid hormone production and secretion, resulting in hyperthyroidism (14). Expression of TSHR outside the thyroid gland has been observed in retroorbital and pretibial tissues, causing some of the extrathyroidal manifestations of the disease. In addition to genetic susceptibility, smoking is a noticeable environmental dose-dependent risk factor for GD and especially for Graves ophthalmopathy. Smoking is associated with recurrence of GD hyperthyroidism, as well as a higher risk of worsening eye changes related to Graves ophthalmopathy after radioiodine therapy and a less favorable outcome of Graves ophthalmopathy treatment with steroids or retrobulbar irradiation. Although the exact pathophysiologic basis of this effect is unclear, it might be related to the fact that cigarette smoking enhances the production of interleukin-1 during the immune response, therefore possibly stimulating growth of orbital fibroblasts. Smoking may also induce hypoxia in fibroblasts, enhancing hyaluronic acid production and adipogenesis $(12,15)$. Polymorphisms in genes encoding for enzymes involved in the biotransformation of xenobiotics are associated with smoking-related GD susceptibility (16). Antithyroglobulin and antithyroperoxidase antibodies are often present in the serum of patients with GD.

TMNG causes hyperthyroidism when nonfunctioning and functioning nodules coexist and, over time, become autonomous, secreting thyroid hormone independently of circulating levels of TSH (17). Follicles in TMNG have a heterogeneous pattern of iodine uptake, displaying either low (cold follicle) or high (hot follicle) iodine uptake on radioiodine scans (18).

TA is a monoclonal well-defined encapsulated benign tumor secreting thyroid hormone in the absence of a TSH stimulus in an otherwise normal gland. It is characterized by increased iodine transport and iodination rate, with increased expression of thyroperoxidase and sodium iodide symporter messenger RNA. In most cases, an activating gain-of-function TSHR mutation confined 
TABLE 1

Summary of Main Physiologic Actions of Thyroid Hormones in Children and Adults

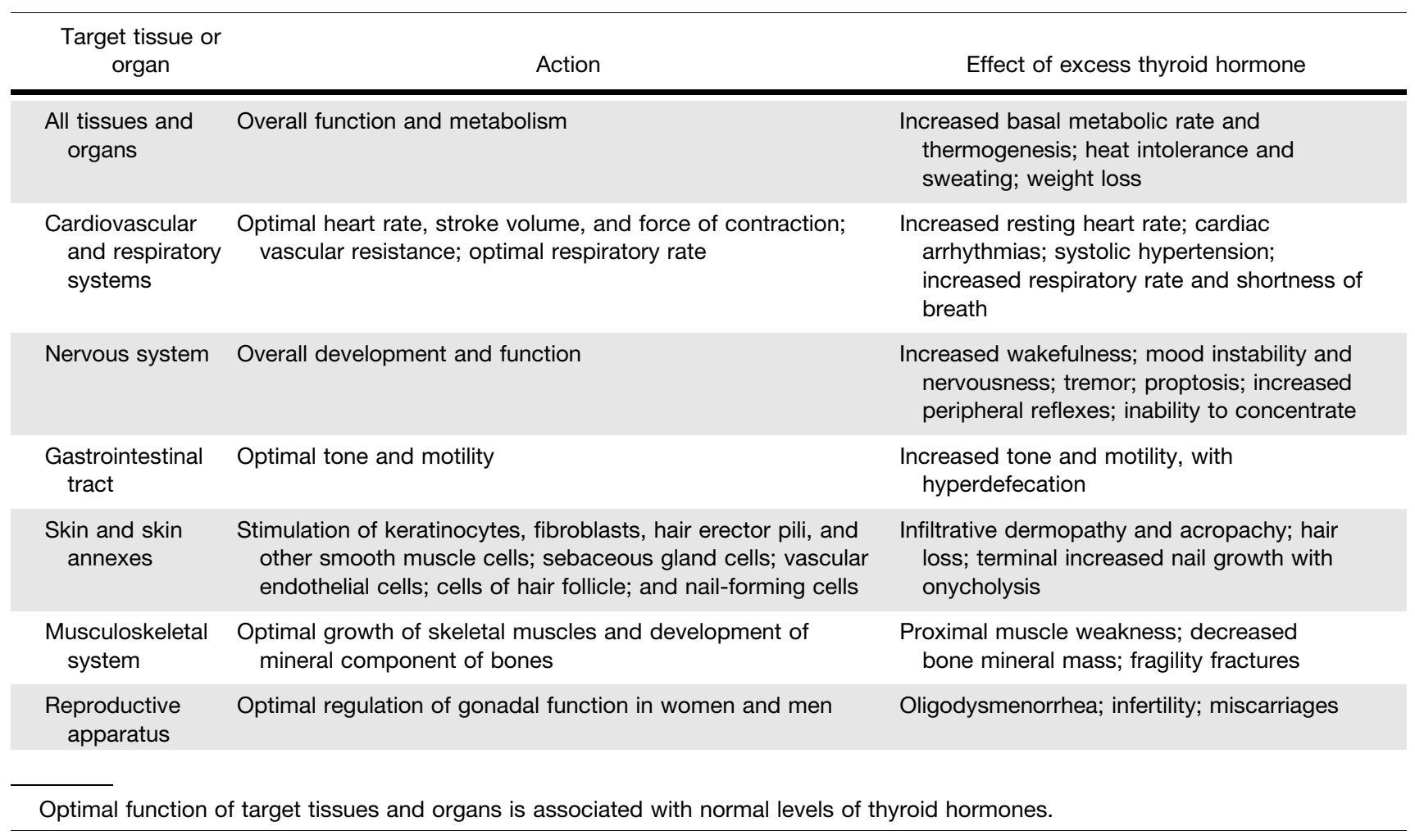

to the adenomatous tissue (somatic mutation) results in stimulation of adenylyl cyclase and intracellular cyclic adenosine monophosphate accumulation, with a consequent increased replication rate of thyroid cells $(19,20)$. Similar to toxic adenoma, gain-of-function TSHR mutations are responsible for the genesis of hyperfunctioning nodules in TMNG (17). Germline mutations of the same gene are responsible for other rare familial forms of nonimmune hyperthyroidism (20). The prevalence of somatic TSHR mutations is up to $82 \%$ of TAs and up to $60 \%$ of hyperfunctioning nodules within a TMNG (21). Iodine deficiency also has a critical role in the development of thyroid autonomy (22).

\section{LAB TESTS}

Elevated levels of serum free-thyroxine and free-triiodothyronine combined with low or suppressed serum TSH confirm the diagnosis of hyperthyroidism. Subclinical hyperthyroidism is defined as low serum TSH with normal serum free-thyroxine and free-triiodothyronine concentrations. In GD, the ratio of triiodothyronine to thyroxine in thyroid secretion is increased because of relative overproduction of triiodothyronine. Elevation of free-thyroxine alone (thyroxine thyrotoxicosis) with a normal level of free-triiodothyronine and undetectable TSH may be found in patients with concomitant severe illnesses, because of enhanced conversion of thyroxine to reversetriiodothyronine (a hormonally inactive form) rather than to active triiodothyronine in peripheral tissues (23). As a compound containing 3 iodine atoms per molecule, triiodothyronine can be the major secretory product in iodine deficiency, because deficiency of iodine favors the production of this hormone over the production of thyroxine-containing 4 iodine atoms per molecule. In this condition, the serum triiodothyronine level is increased (triiodothyronine thyrotoxicosis) with a normal level of free-thyroxine and undetectable TSH. TSHR is the primary antigen in Graves orbitopathy, and patients with the most severe ocular involvement have high titers of TRAb that correlate with the severity of eye disease. Similarly, TRAb levels are usually extraordinarily high in patients with pretibial myxedema.

\section{AMIODARONE-INDUCED THYROID DYSFUNCTION}

Hyperthyroidism can be caused by amiodarone, the most effective drug for long-term maintenance of sinus rhythm in patients with paroxysmal and persistent atrial fibrillation. The incidence of amiodarone-induced thyroid dysfunction ranges between $2 \%$ and $24 \%$. Hyperthyroidism occurs in $1 \%-10 \%$ of amiodarone-treated patients. There are 2 main forms of amiodarone-induced thyrotoxicosis (AIT). Type 1 AIT occurs in patients with abnormal thyroid glands as the result of excessive iodine-induced hormone synthesis and release. A maintenance amiodarone dose of $200 \mathrm{mg} / \mathrm{d}$ contains about $75 \mathrm{mg}$ of iodine (about 500-fold higher than the average daily requirement of iodine). Type 2 AIT, a destructive thyroiditis leading to release of preformed thyroid hormones from the damaged thyroid follicular cells, typically occurs in patients without underlying thyroid disease.

Typical laboratory features of AIT include a low level of serum TSH and an increased level of serum free-thyroxine, whereas the level of free-triiodothyronine can be normal in as many as $80 \%$ of patients treated with amiodarone.

Clinical features such as unexplained weight loss, proximal myopathy, exacerbation of arrhythmia, angina pectoris, or heat intolerance in patients treated with amiodarone suggest the occurrence of this complication; however, classic signs of hyperthyroidism 
may be absent because amiodarone reduces conversion of thyroxine to triiodothyronine in peripheral tissues.

\section{ULTRASOUND IMAGING}

Ultrasonography is essential to determining the size and vascularity of the thyroid gland, as well as the location, size, number, and characteristics of thyroid nodules. In most patients with GD, the thyroid gland is enlarged and diffusely hypoechoic because of increased intrathyroidal flow, increased cellularity, decreased colloid content, and a variable degree of lymphocytic infiltration (Fig. 1). Color Doppler ultrasonography reveals increased vascularity (correlated with the degree of hyperthyroidism) (Fig. 2) and can distinguish between GD and other causes of thyrotoxicosis, such as destructive thyroiditis or exogenous ingestion of thyroid hormones (thyrotoxicosis factitia), which is not associated with increased thyroid perfusion. Color Doppler sonography can also distinguish type 1 from type 2 AIT, the latter being characterized by reduced perfusion, versus type 1 AIT.

TMNGs are generally larger than diffuse goiters, with a heterogeneous echographic structure and multiple nodules of varying size and echogenicity (Fig. 3). Functioning and nonfunctioning thyroid nodules generally coexist. Ultrasound-guided fine-needle aspiration can be considered only for the hypofunctioning areas, since cancer in a scintigraphically hot thyroid nodule is exceedingly rare (24). Instead, TA appears as a solid, iso- or hypoechoic, well-defined nodule with peripheral-edge and peri- or intranodular vascularization (Fig. 4).

\section{THYROID SCINTIGRAPHY}

Increased iodine turnover typical of hyperfunctioning thyroid tissue dictates the scintigraphic patterns commonly observed in patients with the different forms of hyperthyroidism. Provided there has been no use of antithyroid drugs or iodinated contrast materials in the weeks before imaging (Table 2), hyperfunctioning thyroid tissue shows markedly increased uptake of radioiodine ( ${ }^{123} \mathrm{I}$ or ${ }^{131} \mathrm{I}$-iodide) or of ${ }^{99 \mathrm{~m}} \mathrm{Tc}$-pertechnetate. In GD, this process involves the entire thyroid (Fig. 5A), since the cause of hyperfunction is circulating TRAb, which targets all the TSHR-expressing thyroid cells. In the case of TA or TMNG, increased tracer uptake is confined to the hyperfunctioning nodule or nodules. Since TSH secretion is typically suppressed in hyperthyroidism, the normal thyroid parenchyma outside the nodule or nodules with the mutation is in a quiescent state and therefore does not concentrate radioiodine or ${ }^{99 \mathrm{~m}} \mathrm{Tc}$-pertechnetate (Fig. 5B). In TMNG, different nodules can exhibit a patchy pattern with different levels of tracer

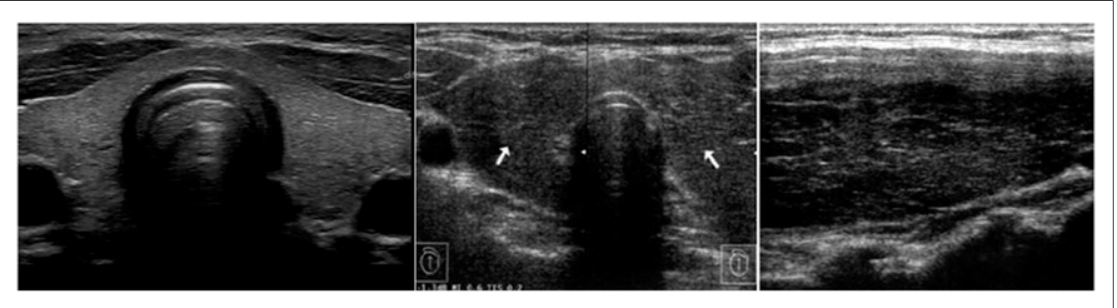

FIGURE 1. Left panel shows typical ultrasound pattern of normal thyroid gland as depicted in axial view; thyroid parenchyma is homogeneous and has echogenicity similar to that of muscles. Center panel (axial view) and right panel (longitudinal view) show typical ultrasound pattern in patient with GD; in this case, thyroid parenchyma exhibits diffusely reduced echogenicity (arrows) and inhomogeneous appearance.

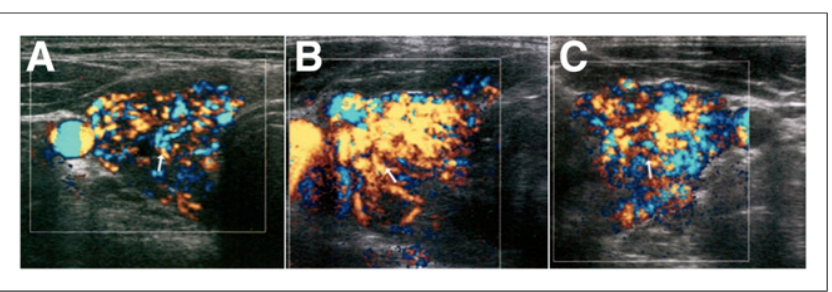

FIGURE 2. Color Doppler evaluation of thyroid in GD. Axial views show diffusely increased parenchymal vascularity (arrows) in right lobe (A and $\mathrm{B})$ and in left lobe (C) of thyroid gland.

uptake (Fig. 5C); areas without uptake are not rare within large hyperfunctioning nodules, reflecting areas of regression. In either GD or toxic nodular goiter, the markedly enhanced tracer uptake in the hyperfunctioning thyroid parenchyma often reduces visualization of physiologic tracer uptake in the salivary glands.

In thyroiditis, thyroid scintigraphy shows reduced or absence of tracer uptake in the hyperthyroid phase of subacute, destructive thyroiditis (Fig. 5D), as well as in thyrotoxicosis factitia. In AIT, 2 different pathophysiologic mechanisms lead to low or no visualization of the gland on thyroid scintigraphy. Radioiodine or ${ }^{99 \mathrm{~m}} \mathrm{Tc}-$ pertechnetate thyroid scintigraphy cannot distinguish type 1 AIT (in which high iodine loading from amiodarone therapy reduces both iodine trapping and organification on a background of nonTMNG) from type 2 AIT (in which increased release of thyroid hormones is due to amiodarone-induced thyroid gland inflammation). The 2 forms of AIT can be distinguished by thyroid scintigraphy with $99 \mathrm{~m} \mathrm{Tc}$-sestamibi, which shows preserved tracer uptake in type 1 and reduced or absence of uptake in type 2 (25).

\section{RADIOIODINE UPTAKE (RAIU) TEST}

The RAIU test has a very limited role in the diagnosis of thyroid disorders (26). However, it provides essential information in hyperthyroid patients scheduled for therapy with ${ }^{131}$ I-iodide (27-29). It allows pretreatment radiation dosimetry estimates aimed at tailoring the administered radioiodine activity to the actual need in individual patients, according to the "as low as reasonably achievable" principle (30).

In hyperthyroidism due to GD, TMNG, or TA, the RAIU values are higher than in euthyroid subjects, both at 3-4 h and at $24 \mathrm{~h}$ (Fig. 6) after tracer administration. In rare instances with early thyroidal hormone discharge, measurement at $6 \mathrm{~h}$ is also helpful, as the RAIU value is lower at $24 \mathrm{~h}$ than at $6 \mathrm{~h} \mathrm{(31).}$

Some nuclear medicine centers estimate thyroid function from thyroid scintigraphy with ${ }^{99 \mathrm{~m}}$ Tc-pertechnetate by determining the percentage of ${ }^{99 m}$ Tc-pertechnetate uptake at $20 \mathrm{~min}$. In euthyroid subjects, this parameter ranges between $0.5 \%$ and $2 \%$ of the injected activity (32). ${ }^{99 \mathrm{~m} T c-p e r t e c h n e t a t e}$ uptake cannot, unfortunately, guide selection of the activity of ${ }^{131}$ I-iodide to be administered for therapy.

\section{THERAPY OF HYPERTHYROIDISM WITH ${ }^{131}$ I-IODIDE}

Three options are available to treat patients with hyperthyroidism (33-35): antithyroid 


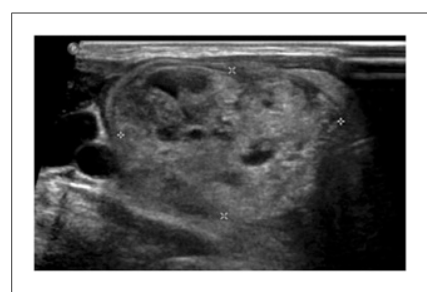

FIGURE 3. Ultrasound longitudinal view showing heterogeneous pattern with multiple nodules that have varying echogenicity and size, consistent with TMNG. response (normalization of circulating thyroid hormones and improvement of signs or symptoms), there is a high rate of disease recurrence after tapering or cessation of therapy, more than $90 \%$ in TMNG (36) and 40\%-50\% in GD (37). To minimize recurrence, antithyroid drug therapy must be continued for months to years. Patients treated with long-term medical therapy may develop adverse reactions ranging from minor (skin rashes) to major (e.g., agranulocytosis or hepatitis). As a result, these patients must have regular laboratory studies and clinical follow-up visits.

Surgery is generally reserved for selected patients with recurrent GD or TMNG that is not controlled by medical therapy, especially if the abnormally enlarged thyroid gland compresses neighboring structures. Surgery is also indicated in patients with severe Graves ophthalmopathy.

\section{Mechanism of Action of Radioiodine}

$\beta^{-}$particles emitted by ${ }^{131} \mathrm{I}$ are responsible for about $94 \%$ of the radiobiologic effects of this radioisotope. The maximum energy of these $\beta^{-}$particles is $0.61 \mathrm{MeV}$, with an average value of $0.192 \mathrm{MeV}$; the average range in soft tissues is approximately $0.4 \mathrm{~mm}$, with a maximum range of about $3 \mathrm{~mm}$. The radiobiologic effects of ${ }^{131} \mathrm{I}$ in tissues can be either indirect (caused by the interaction of radiation with water, producing free radicals, which

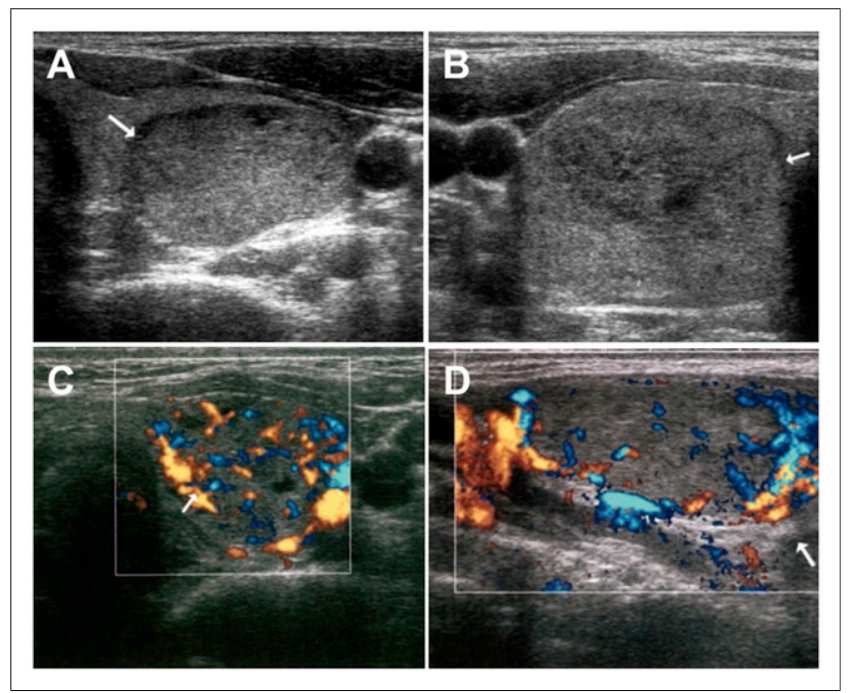

FIGURE 4. Ultrasound patterns in patients with toxic adenoma (axial views in $A, B$, and $C$; longitudinal view in $D$ ): solid hypoechoic or isoechoic nodules (A and B) with well-defined peripheral edge (arrows in A and $B$ ). Color Doppler evaluation shows increased intranodular (C) or perinodular (D) vascularization (indicated by arrows in $C$ and $D$ ).
TABLE 2

Factors Interfering with Thyroid Uptake of Radioiodine, and Recommended Minimal Withdrawal Time Before Radioiodine Therapy

\begin{tabular}{ll}
\hline \multicolumn{1}{c}{ Compound } & Withdrawal time \\
\hline Thyroid-related medications & \\
\hline Antithyroid drugs ${ }^{\star}$ & $3-7 \mathrm{~d}$ to $2-3 \mathrm{wk}$ \\
\hline Perchlorate & $1 \mathrm{wk}$ \\
\hline lodinated drugs or substances & \\
\hline Amiodarone & $3-6 \mathrm{mo}$ \\
\hline Intravenous contrast agents ${ }^{\dagger}$ & $2-4 \mathrm{wk}$ \\
\hline lodine-containing preparations & $4 \mathrm{wk}$ \\
\hline Lugol solution or SSKI & $4-6 \mathrm{wk}$ \\
\hline Kelp or seaweed & $2-4 \mathrm{wk}$ \\
\hline Oil-based contrast agents ${ }^{\ddagger}$ & $3-6 \mathrm{mo}$ \\
\end{tabular}

*Methimazole, carbimazole, and propylthiouracil: longer withdrawal for methimazole, shorter for propylthiouracil.

${ }^{\dagger}$ Currently used nonionic contrast agents undergo fast renal clearance, thus possibly requiring shorter withdrawal times.

${ }^{\ddagger}$ Rarely used in current clinical practice.

SSKI = supersaturated potassium iodide solution.

interact with critical macromolecules in the cell) or direct (when radiation deposited within the cell nucleus causes both singlestrand and double-strand DNA damage leading to cell death). This combined radiobiologic effect causes cellular apoptosis or necrobiosis, with destruction of the thyroid follicles and replacement of thyroid parenchyma with fibrotic tissue. The ultimate effect of this form of therapy is therefore comparable to surgical removal of the thyroid tissue undergoing such internal radiation.

The aim of radioiodine therapy in patients with TA or TMNG is to achieve a euthyroid status. In patients with GD, the goal is to produce a hypothyroid status. The euthyroid status in TMNG or TA is feasible because only the nodules bearing the somatic mutation causing autonomous activation of the TSHR concentrate radioiodine. The extranodular thyroid parenchyma is spared most of the radiobiologic damage in the hyperfunctioning nodules. When the hyperfunctioning nodules have regressed because of radiationinduced apoptosis or necrobiosis, the extranodular parenchyma will resume normal or near-normal functioning $(38,39)$.

In GD, all the thyroid cells are exposed to the stimulation of circulating TRAbs. In these conditions, a euthyroid status possibly achieved after radioiodine therapy means that treatment has induced apoptosis or necrobiosis of most but not all thyroid cells, leaving sufficient viable thyroid parenchyma to ensure production of thyroid hormones and keep their circulating levels within normal values. However, the underlying pathophysiologic mechanism causing GD, the circulating TRAb, has not been cured; therefore, the residual viable thyroid cells will undergo continuous stimulation, and sooner or later the disease will recur. For this reason, the goal of radioiodine therapy in patients with GD is to render them permanently hypothyroid-a status treatable with oral thyroid hormone replacement therapy $(34,35)$.

\section{Indications}

Radioiodine therapy of hyperthyroidism is indicated for patients with GD, TMNG, or TA who are intolerant or unresponsive to 


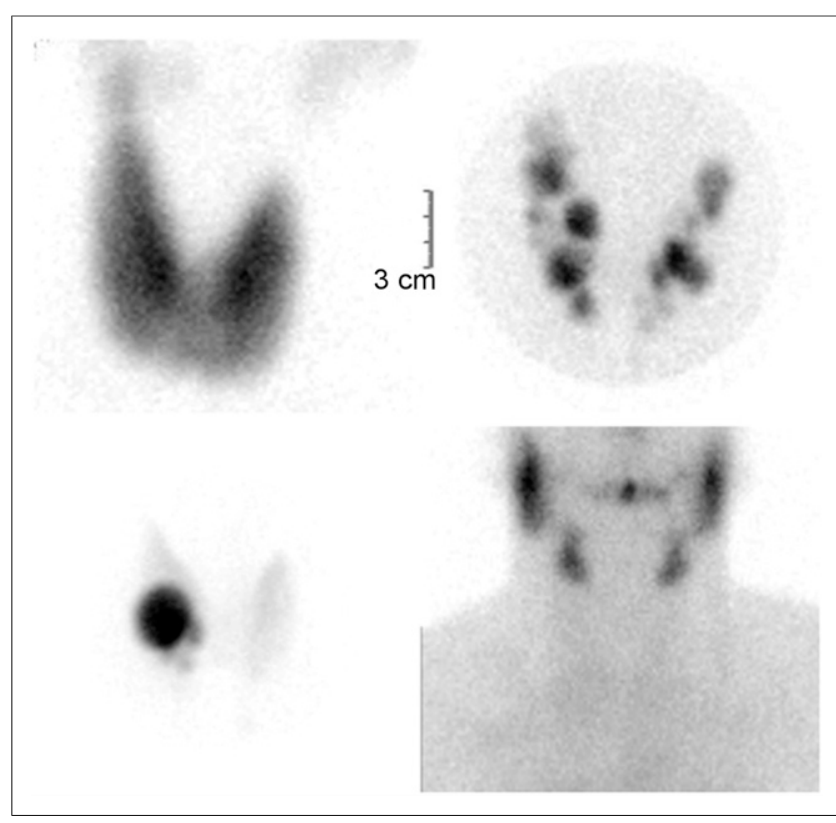

FIGURE 5. Different scintigraphic patterns in patients with hyperthyroidism, obtained with ${ }^{99 m T c-p e r t e c h n e t a t e . ~(U p p e r ~ l e f t) ~ T y p i c a l ~ p a t t e r n ~}$ of thyroid scintigraphy observed in GD, with markedly increased tracer uptake and diffuse enlargement involving whole gland. (Upper right) Thyroid scintigraphy (pinhole collimator) in TMNG, showing multiple nodules with different degrees of tracer uptake in both lobes and suppressed uptake in extranodular parenchyma. (Lower left) Thyroid scintigraphy (pinhole collimator) in patient with single hyperfunctioning nodule, showing markedly increased tracer uptake in right lobe nodule and virtual absence of tracer in remainder of gland. (Lower right) Thyroid scintigraphy in patient with transient hyperthyroidism caused by subacute thyroiditis, showing absence of tracer uptake in thyroid gland; physiologic activity in salivary glands is well visualized.

treatment with antithyroid drugs, have mild or moderate orbitopathy, or refuse or cannot undergo surgery because of comorbidities $(28,33-35,40)$. Indications for radioiodine therapy in patients with severe Graves orbitopathy should be carefully balanced against possible important side effects (see further below).

Although radioiodine therapy is a first-line option for treatment, the trend for choosing this option is declining in the United States (41). The guidelines issued in 2016 by the American Thyroid Association (34) list the clinical conditions that-in addition to intolerance or resistance to antithyroid drugs_-indicate radioiodine therapy: comorbidities increasing the general surgical risk; prior neck surgery or irradiation of the neck; lack of access to a high-volume thyroid surgeon; and periodic thyrotoxic hypokalemic paralysis, right heart failure due to pulmonary hypertension, or congestive heart failure.

In addition to these indications, the 2018 European Thyroid Association guideline for the management of Graves hyperthyroidism (35) recommends also considering radioiodine therapy in cases of mild hyperthyroidism (even with a serum TSH level of between 0.1 and $0.39 \mu \mathrm{IU} / \mathrm{mL}$ ), given the high potential for progression of this condition to a more severe state of hyperthyroidism and the increased risk of acute cardiac events and mortalityespecially in patients older than $65 \mathrm{y}$.

\section{Contraindications}

Therapy of hyperthyroidism with ${ }^{131}$ I-iodide is contraindicated in some well-established conditions, although with some variations

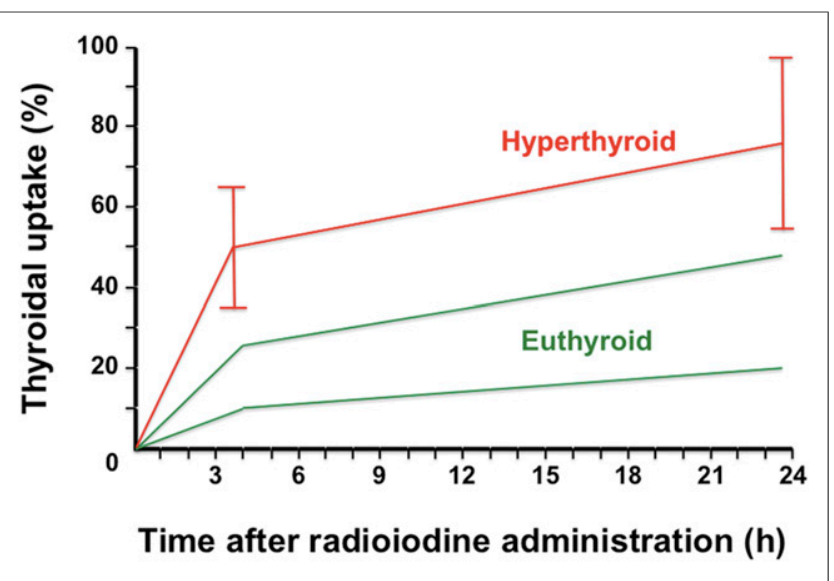

FIGURE 6. Schematic plot of RAIU measured with external y-probe at 4 and $24 \mathrm{~h}$ after oral administration of ${ }^{131}$ I-iodide tracer; values are corrected for physical decay of ${ }^{131}$ I. Green lines indicate range of values observed in subjects with normal thyroid function; actual values may vary from one geographic area to another, depending on dietary iodine intake. Red line represents average value (with $95 \% \mathrm{Cls}$ ) calculated in representative sample of 25 consecutive patients with GD scheduled for radioiodine therapy at Regional Center of Nuclear Medicine, University Hospital of Pisa.

regarding absolute or relative criteria. Pregnancy and breastfeeding are absolute contraindications. Other contraindications (considered as absolute by some guidelines and as relative by other guidelines) include an inability to comply with radiation safety recommendations, coexisting or suspected thyroid cancer, pregnancy planned within 6 mo after radioiodine therapy, and uncontrolled hyperthyroidism. Radioiodine therapy should be considered with great caution in patients with Graves ophthalmopathy (especially if smokers) because cell damage induced by radiation causes release into the circulation of thyroid antigens that enhance the immunogenic stimulation leading to TRAb production, therefore promoting de novo or worsening Graves orbitopathy (42-45).

Before receiving radioiodine therapy, the patient must provide a detailed medical history describing previous treatments or procedures such as antithyroid drugs, radiographic studies with iodinated contrast medium, therapy with amiodarone or other iodine-containing medications, and recent consumption of iodinerich food. Full characterization of patients includes laboratory testing confirming hyperthyroidism, thyroid scintigraphy, RAIU testing, ultrasonography to assess the thyroid target volume (or MRI in cases of intrathoracic extension), and a negative pregnancy test in women of childbearing age (40). Fine-needle aspiration of thyroid nodules, especially of those that appear to be hypofunctioning on thyroid scintigraphy, must be considered in cases of suggestive ultrasonography features (solid composition, hypoechogenicity, taller-than-wide shape, irregular margin, extrathyroidal extension, punctate echogenic foci), according to the risk stratification system for thyroid nodules (American College of Radiology Thyroid Imaging Reporting and Data System; https:// www.acr.org/Clinical-Resources/Reporting-and-Data-Systems/TIRADS) (46). On this basis, thyroid nodules are stratified into 5 risk levels, from TR1 (benign) to TR5 (high suspicion of malignancy). Fine-needle aspiration is recommended for nodules classified as TR3-TR5, except for nodules smaller than $1 \mathrm{~cm}$ in diametereven if showing highly suggestive ultrasonography features. In this instance, active surveillance is recommended. 
In patients with large goiters (especially if $>80 \mathrm{~cm}^{3}$ with intrathoracic extension), radiation-induced inflammation may cause swelling of the thyroid parenchyma, causing narrowing of the tracheal lumen, especially in long-standing bulky goiters-which weakens the cartilage structure of the trachea. The physician must explain the procedure, possible complications and side effects, therapeutic alternatives, and expected outcome. Breastfeeding women must be advised to stop breastfeeding, and therapy should be delayed until lactation ceases, to minimize the radiation dose both to the child and to the breast.

\section{Preparation}

Preparation for radioiodine therapy is aimed at optimizing concentration of ${ }^{131}$ I-iodide in the hyperfunctioning thyroid parenchyma (the whole gland in GD, the hyperfunctioning nodules in TMNG and TA). Antithyroid drugs must be discontinued for at least $2-3 \mathrm{wk}$ in the case of carbimazole and methimazole and at least $3 \mathrm{~d}$ in the case of propylthiouracil. If symptoms of hyperthyroidism recur during the interval of drug withdrawal, $\beta$-blocking drugs can usually control symptoms. In hyperthyroid patients for whom radioiodine therapy is selected as the first-line option, a brief course of antithyroid drug treatment is suggested to deplete the intrathyroidal hormone stores by blocking iodination of tyrosine while the gland continues to respond to TRAb with release of previously formed thyroid hormone, especially in elderly patients and patients with preexisting heart disease or severe systemic illness $(40,47)$.

Patients must discontinue use of iodide-containing medications for at least 2-3 wk, except for amiodarone-which requires withdrawals for months while monitoring urinary iodine excretion) (28). Although many European centers prepare patients with a low-iodine diet for 10-15 d before administering radioiodine therapy (48), in the United States the low-iodine diet is reserved for therapy in patients with thyroid cancer. Some centers prescribe lithium starting $7 \mathrm{~d}$ before administering radioiodine ( $250 \mathrm{mg} 3$ times daily) to block radioiodine release from the thyroid gland without interfering with its uptake $(49,50)$, although this practice is not widely used.

\section{Radioiodine Activity to Be Administered}

The dose of ${ }^{131} \mathrm{I}$-iodide to treat hyperthyroidism is still a matter of debate. A practical approach is to administer a fixed activity (185, 370, or $555 \mathrm{MBq}$ ) empirically based on the severity of thyrotoxicosis, size of goiter, and RAIU value (51); in some countries, $555 \mathrm{MBq}$ is the maximum ${ }^{131}$ I activity that can be administered on an outpatient basis. Alternatively, the ${ }^{131}$ I-iodide activity is based on a fixed value of target-absorbed dose and on MIRD formulations using the thyroid gland size and 24-h RAIU value $(27,28)$ or on the effective radioiodine half-life in the thyroid gland (52). Recommended radiation doses range from 150 to 300 Gy to treat GD and from 300 to 400 Gy to treat autonomously functioning nodules $(29,40)$. Some authors assume that ${ }^{131} \mathrm{I}$ at an activity of 3.7-5.5 MBq/g delivers a radiation dose of 100-150 Gy to the tissue (24); according to other estimates, an activity of 3-8 $\mathrm{MBq} / \mathrm{g}$ of thyroid tissue yields an acceptable cure rate (28).

Practical examples of the different approaches used to calculate either the thyroid-targeted activity or the thyroid-absorbed radiation dose $(28,29,53-56)$ are given in the supplemental materials (available at http://jnm.snmjournals.org).

To maximize the rate of gastrointestinal absorption of orally administered ${ }^{131} \mathrm{I}$-iodide, patients should fast for at least $4 \mathrm{~h}$ before therapy. The patient should be instructed to drink at least $1 \mathrm{~L}$ of water in the hour after treatment.

\section{Effectiveness of Radioiodine Therapy}

The effectiveness of therapy with ${ }^{131}$ I-iodide for hyperthyroidism is evaluated by clinical and laboratory parameters, usually at 3 , 6, and 12 mo after treatment $(34,41)$. For GD patients, most authors base such an evaluation on the elimination of hyperthyroidism, that is, a state of either euthyroidism or hypothyroidism compensated by L-thyroxine administration. For patients with hyperfunctioning thyroid nodules, the goal of treatment is to restore euthyroidism, as well as to reduce volume - assessed by ultrasound and occasionally by thyroid scintigraphy.

\section{Side Effects of Radioiodine Therapy}

Early Side Effects. Early side effects of ${ }^{131}$ I-iodide therapy are due to acute injury to the thyroid cells or follicles induced by radiation. This injury results in rapid discharge of thyroid hormones stored in the follicle colloid, thus causing a transient rise in the circulating free-triiodothyronine and free-thyroxine levels at approximately 5-10 d after radioiodine therapy. Symptoms of hyperthyroidism may therefore become exacerbated, including heart arrhythmias, which can be well controlled with $\beta$-blockers. A common clinical practice is also to start administration of antithyroid drugs 3-4 d after administration of ${ }^{131}$ I-iodide, usually at the same dosage as was used to control hyperthyroidism; antithyroid therapy is tapered and discontinued over the following 2-4 wk.

Radiation-induced inflammation can also cause pain and swelling of the thyroid gland, which are usually ameliorated with either steroidal or nonsteroidal antiinflammatory drugs, depending on the severity of symptoms. In the case of large goiters (especially those with intrathoracic extension), the swelling may cause dyspnea, which can be treated with corticosteroids. In contrast to thyroid cancer patients treated with high-dose radioiodine, sialoadenitis due to physiologic accumulation of ${ }^{131}$ I-iodide in the salivary glands is rarely experienced in patients treated for hyperthyroidism.

Delayed Side Effects. Fixed-dose radioiodine therapy achieves the goal of successful treatment (hypothyroidism) in about $80 \%$ of patients. Patients who fail to become hypothyroidal after about 6 mo can undergo a second treatment, which is effective in about $90 \%$ of cases. Surgery should be considered for patients in whom 2 courses of radioiodine therapy fail. It is important to follow patients in whom radioiodine therapy fails, since hypothyroidism develops at a rate of about 5\%/y after radioiodine therapy (57).

Hypothyroidism occurs in less than $10 \%$ of patients with a solitary toxic nodule treated with radioiodine. Euthyroidism is usually achieved within 3-12 mo after therapy (38,58-60). In TMNG patients, the incidence of hypothyroidism ranges between $20 \%$ and $75 \%$ within 8 y after radioiodine therapy (58). After radioiodine therapy, the thyroid parenchyma is progressively replaced by fibrotic tissue (59), appearing hypovascular and coarsely hyperechoic on ultrasound (61).

Ophthalmopathy may occur-or worsen if already present-in GD patients after therapy with radioiodine (38), particularly in smokers, in patients with severe hyperthyroidism and high TRAb levels, and in patients with a recent onset of hyperthyroidism; this effect is due to release of thyroid antigens by the dying thyroid cells, causing stimulation of the immune events associated with ophthalmopathy $(42-45,62)$. When radioiodine therapy is selected for patients with ophthalmopathy, oral corticosteroid prophylaxis beforehand should be considered to minimize exacerbation of ophthalmopathy (63).

Impairment of both male and female fertility has been reported after treatment with high-dose radioiodine for differentiated 
thyroid cancer (64-67), although more recent data contradict this notion (68). Although reduced fertility is not a common concern for the relatively low-dose treatments administered to patients with hyperthyroidism, a waiting time before conception is commonly recommended: at least 6 mo in women, to ensure that the patient is euthyroid and on a stable dose of hormone replacement, and 4 mo in men, to allow turnover of sperm production.

Fear of radiation-induced malignancies after radioiodine therapy in thyroid cancer patients is not new (69-71), although not justified by analysis of follow-up data $(72,73)$. Similar concern has recently been raised in the case of hyperthyroidism (74). This notion has been strongly refuted (75-79).

The newly released guideline from the U.K. National Institute for Health and Care Excellence (https://www.nice.org.uk/guidance/ng145) supports therapy of hyperthyroidism with ${ }^{131} \mathrm{I}$-iodide as a safe and cost-effective medical practice. About $77 \%$ of endocrinologists in Europe offer antithyroid drug treatment as first-line therapy for newly diagnosed, uncomplicated GD, versus $40 \%$ of specialists in North America, where RAI currently remains the preferred primary treatment for GD. Another difference between European and North American specialists is that antithyroid drug treatment to restore euthyroidism before RAI treatment is widely used in Europe, whereas in North America it is generally used only in the presence of cardiovascular problems $(80)$.

\section{REFERENCES}

1. Vanderpump MPJ. The epidemiology of thyroid disease. Br Med Bull. 2011;99:39-51.

2. Garmendia Madariaga A, Palacios SS, Guillèn-Grima F, Galofré JC. The incidence and prevalence of thyroid dysfunction in Europe: a meta-analysis. J Clin Endocrinol Metab. 2014;99:923-931.

3. Singer PA, Cooper DS, Levy EG, et al. Treatment guidelines for patients with hyperthyroidism and hypothyroidism. Standards of Care Committee, American Thyroid Association. JAMA. 1995;273:808-812.

4. Hollowell JG, Staehling NW, Flanders WD, et al. Serum TSH, $\mathrm{T}_{4}$, and thyroid antibodies in the United States population (1988 to 1994): National Health and Nutrition Examination Survey (NHANES III). J Clin Endocrinol Metab. 2002; 87:489-499.

5. Vanderpump MP, Tunbridge WM, French JM, et al. The incidence of thyroid disorders in the community: a twenty-year follow-up of the Whickham Survey. Clin Endocrinol (Oxf). 1995;43:55-68.

6. Jasim S, Gharib H. Thyroid and aging. Endocr Pract. 2018;24:369-374.

7. van Hulsteijn LT, Pasquali R, Casanueva F, et al. Prevalence of endocrine disorders in obese patients: systematic review and meta-analysis. Eur J Endocrinol. 2020;182:11-21.

8. Baumann E. On the normal occurrence of iodine in the animal body [in German]. Hoppe Seylers Z Physiol Chem. 1895;21:319-330.

9. Dremier S, Coppée F, Delange F, Vassart G, Dumont JE, Van Sande J. Clinical review 84: thyroid autonomy: mechanism and clinical effects. J Clin Endocrinol Metab. 1996;81:4187-4193.

10. McDermott MT, Ridgway EC. Central hyperthyroidism. Endocrinol Metab Clin North Am. 1998;27:187-203.

11. Laurberg P, Pedersen KM, Vestergaard H, Sigurdsson G. High incidence of multinodular toxic goitre in the elderly population in a low iodine intake area vs. high incidence of Graves' disease in the young in a high iodine intake area: comparative surveys of thyrotoxicosis epidemiology in East-Jutland Denmark and Iceland. J Intern Med. 1991;229:415-420.

12. Wiersinga WM. Smoking and thyroid. Clin Endocrinol (Oxf). 2013;79:145-151.

13. Eschler DC, Hasham A, Tomer Y. Cutting edge: the etiology of autoimmune thyroid diseases. Clin Rev Allergy Immunol. 2011;41:190-197.

14. Orgiazzi J, Williams DE, Chopra IJ, Solomon DH. Human thyroid adenyl cyclasestimulating activity in immunoglobulin G of patients with Graves' disease. J Clin Endocrinol Metab. 1976;42:341-354.

15. Metcalfe RA, Davies RAP, Weetman AP. Analysis of fibroblast-stimulating activity in IgG from patients with Graves' dermopathy. Thyroid. 1993;3:207-212.

16. Bufalo NE, Santos RB, Cury AN, et al. Genetic polymorphisms associated with cigarette smoking and the risk of Graves' disease. Clin Endocrinol (Oxf). 2008; 68:982-987.
17. Tonacchera M, Chiovato L, Pinchera A, et al. Hyperfunctioning thyroid nodules in toxic multinodular goiter share activating thyrotropin receptor mutations with solitary toxic adenoma. J Clin Endocrinol Metab. 1998;83:492-498.

18. Krohn K, Wohlgemuth S, Gerber H, Paschke R. Hot microscopic areas of iodinedeficient euthyroid goitres contain constitutively activating TSH receptor mutations. J Pathol. 2000;192:37-42.

19. Parma J, Van Sande J, Swillens S, Tonacchera M, Dumont J, Vassart G. Somatic mutations causing constitutive activity of the thyrotropin receptor are the major cause of hyperfunctioning thyroid adenomas: identification of additional mutations activating both the cyclic adenosine 3',5'-monophosphate and inositol phosphate-Ca ${ }^{2+}$ cascades. Mol Endocrinol. 1995;9:725-733.

20. Tonacchera M, Van Sande J, Parma J, et al. TSH receptor and disease. Clin Endocrinol (Oxf). 1996;44:621-633.

21. Tonacchera M, Agretti P, Chiovato L, et al. Activating thyrotropin receptor mutations are present in nonadenomatous hyperfunctioning nodules of toxic or autonomous multinodular goiter. J Clin Endocrinol Metab. 2000;85:2270-2274.

22. Hegedüs L, Bonnema SJ, Bennedbaek FN. Management of simple nodular goiter: current status and future perspectives. Endocr Rev. 2003;24:102-132.

23. Köhrle J. Thyroid hormones and derivatives: endogenous thyroid hormones and their targets. Methods Mol Biol. 2018;1801:85-104.

24. Wong R, Farrell SG, Grossmann M. Thyroid nodules: diagnosis and management. Med J Aust. 2018;209:92-98.

25. Piga M, Cocco MC, Serra A, Boi F, Loy M, Mariotti S. The usefulness of ${ }^{99 \mathrm{~m}} \mathrm{Tc}-$ sestaMIBI thyroid scan in the differential diagnosis and management of amiodarone-induced thyrotoxicosis. Eur J Endocrinol. 2008;159:423-429.

26. Giovanella L, Avram AM, Iakovu I, et al. EANM practice guideline/SNMMI procedure standard for RAIU and thyroid scintigraphy. Eur J Nucl Med Mol Imaging. 2019;46:2514-2525.

27. Bonnema SJ, Hegedüs L. Radioiodine therapy in benign thyroid diseases: effects, side effects, and factors affecting therapeutic outcome. Endocr Rev. 2012;33:920-980.

28. Silberstein EB, Alavi A, Balon HR, et al. The SNMMI practice guideline for therapy of thyroid disease with ${ }^{131}$ I 3.0. J Nucl Med. 2012;53:1633-1651.

29. Hänscheid H, Canzi C, Eschner W, et al. EANM Dosimetry Committee series on standard operational procedures for pre-therapeutic dosimetry II. Dosimetry prior to radioiodine therapy of benign thyroid diseases. Eur J Nucl Med Mol Imaging. 2013;40:1126-1134.

30. Bacher K, Thierens HM. Accurate dosimetry: an essential step towards good clinical practice in nuclear medicine. Nucl Med Commun. 2005;26:581-586.

31. Morris LF, Waxman AD, Braunstein GD. Accuracy considerations when using early (four- or six-hour) radioactive iodine uptake to predict twenty-four-hour values for radioactive iodine dosage in the treatment of Graves' disease. Thyroid. 2000;10:779-787.

32. Macauley M, Shawgi M, Ali T, et al. Assessment of normal reference values for thyroid uptake of technetium-99m pertechnetate in a single centre UK population. Nucl Med Commun. 2018;39:834-838.

33. Bahn Chair RS, Burch HB, Cooper DS, et al. American Thyroid Association and American Association of Clinical Endocrinologists. Hyperthyroidism and other causes of thyrotoxicosis: management guidelines of the American Thyroid Association and American Association of Clinical Endocrinologists. Thyroid. 2011; 21:593-646.

34. Ross DS, Burch HB, Cooper DS, et al. 2016 American Thyroid Association guidelines for diagnosis and management of hyperthyroidism and other causes of thyrotoxicosis. Thyroid. 2016;26:1343-1421.

35. Kahaly GJ, Bartalena L, Hegedüs L, Leenhardt L, Poppe K, Pearce SH. 2018 European Thyroid Association guideline for the management of Graves' hyperthyroidism. Eur Thyroid J. 2018;7:167-186.

36. Freitas JE. Therapeutic options in the management of toxic and nontoxic nodular goiter. Semin Nucl Med. 2000;30:88-97.

37. Reinwein D, Benker G, Lazarus JH, Alexander WD. The European multicenter study group on antithyroid drug treatment: a prospective randomized trial of antithyroid drug dose in Graves' disease therapy. J Clin Endocrinol Metab. 1993;76: 1516-1521.

38. Ross DS, Ridgway EC, Daniels GH. Successful treatment of solitary toxic thyroid nodules with relatively low-dose iodine-131, with low prevalence of hypothyroidism. Ann Intern Med. 1984;101:488-490.

39. Nygaard B, Hegedüs L, Nielsen KG, Ulriksen P, Hansen JM. Long-term effect of radioactive iodine on thyroid function and size in patients with solitary autonomously functioning toxic thyroid nodules. Clin Endocrinol (Oxf). 1999;50:197-202.

40. Stokkel MPM, Handkiewicz Junak D, Lassmann M, Dietlin M, Luster M. EANM procedure guidelines for therapy of benign thyroid disease. Eur $\mathrm{J} \mathrm{Nucl}$ Med Mol Imaging. 2010;37:2218-2228.

41. Brito JP, Schilz S, Singh Ospina N, et al. Antithyroid drugs: the most common treatment for Graves' disease in the United States-a nationwide populationbased study. Thyroid. 2016;26:1144-1145. 
42. Tallstedt L, Lundell G, Torring O, et al. Occurrence of ophthalmopathy after treatment for Graves' hyperthyroidism. The Thyroid Study Group. $N$ Engl J Med. 1992;326:1733-1738.

43. Bartalena L, Marcocci C, Bogazzi F, et al. Relation between therapy for hyperthyroidism and the course of Graves' ophthalmopathy. N Engl J Med. 1998;338: 73-78.

44. Acharya SH, Avenell A, Philip S, Burr J, Bevan JS, Abraham P. Radioiodine therapy (RAI) for Graves' disease (GD) and the effect on ophthalmopathy: a systematic review. Clin Endocrinol (Oxf). 2008;69:943-950.

45. Laurberg P, Wallin G, Tallstedt L, Abraham-Nordling M, Lundell G, Tørring O. TSH-receptor autoimmunity in Graves' disease after therapy with anti-thyroid drugs, surgery, or radioiodine: a 5-year prospective randomized study. Eur J Endocrinol. 2008;158:69-75.

46. Tessler FN, Middleton WD, Grant EG, et al. ACR thyroid imaging, reporting and data system (TI-RADS): white paper of the ACR TI-RADS Committee. J Am Coll Radiol. 2017;14:587-595.

47. Kyrilli A, Tang BN, Huyge V, et al. Thiamazole pretreatment lowers the ${ }^{131} \mathrm{I}$ activity needed to cure hyperthyroidism in patients with nodular goiter. J Clin Endocrinol Metab. 2015;100:2261-2267.

48. Tomoda C, Uruno T, Takamura Y, et al. Reevaluation of stringent low iodine diet in outpatient preparation for radioiodine examination and therapy. Endocr J. 2005;52:237-240.

49. Bogazzi F, Bartalena L, Brogioni S, et al. Comparison of radioiodine with radioiodine plus lithium in the treatment of Graves' hyperthyroidism. J Clin Endocrinol Metab. 1999;84:499-503.

50. Bal CS, Kumar A, Pandey RM. A randomized controlled trial to evaluate the adjuvant effect of lithium on radioiodine treatment of hyperthyroidism. Thyroid. 2002;12:399-405.

51. Marinelli LD, Quimby EH, Hine GJ. Dosage determination with radioactive isotopes; practical considerations in therapy and protection. Am J Roentgenol Radium Ther. 1948;59:260-281.

52. Howarth D, Epstein M, Lan L, Tan P, Booker J. Determination of the optimal minimum radioiodine dose in patients with Graves' disease: a clinical outcome study. Eur J Nucl Med. 2001;28:1489-1495.

53. Müller B, Bares R, Büll U. The effective half-life of ${ }^{131}$ I during the treatment of autonomous thyroid disease with radioiodine [in German]. Nucl Med (Stuttg). 1991;30:71-76.

54. Kobe C, Eschner W, Wild M, et al. Radioiodine therapy of benign thyroid disorders: what are the effective thyroidal half-life and uptake of ${ }^{131} \mathrm{I}$ ? $\mathrm{Nucl} \mathrm{Med}$ Commun. 2010;31:201-205.

55. Traino AC, Di Martino F, Grosso M, et al. A predictive mathematical model for the calculation of the final mass of Graves' disease thyroids treated with ${ }^{131} \mathrm{I}$. Phys Med Biol. 2005;50:2181-2191.

56. Orsini F, Traino AC, Grosso M, et al. Personalization of radioiodine treatment for Graves' disease: a prospective, randomized study with a novel method for calculating the optimal ${ }^{131}$ I-iodide activity based on target reduction of thyroid mass. Q J Nucl Med Mol Imaging. 2012;56:496-502.

57. Nygaard B, Hegedüs L, Gervil M, et al. Influence of compensated radioiodine therapy on thyroid volume and incidence of hypothyroidism in Graves' disease. J Intern Med. 1995;238:491-497.

58. Kahraman D, Keller C, Schneider C, et al. Development of hypothyroidism during long-term follow-up of patients with toxic nodular goitre after radioiodine therapy. Clin Endocrinol (Oxf). 2012;76:297-303.

59. Dobyns BM, Vickery AL, Maloof F, Chapman EM. Functional and histologic effects of therapeutic doses of radioactive iodine on the thyroid of man. J Clin Endocrinol Metab. 1953;13:548-567.

60. De Leo S, Lee SY, Braverman LE. Hyperthyroidism. Lancet. 2016;388:906-918.

61. English C, Casey R, Bell M, Bergin D, Murphy J. The sonographic features of the thyroid gland after treatment with radioiodine therapy in patients with Graves' disease. Ultrasound Med Biol. 2016;42:60-67.
62. Regalbuto C, Salamone S, Scollo C, Vigneri R, Pezzino V. Appearance of anti TSH-receptor antibodies and clinical Graves' disease after radioiodine therapy for hyperfunctioning thyroid adenoma. J Endocrinol Invest. 1999;22:147-150.

63. Bartalena L, Baldeschi L, Dickinson A, et al. Consensus statement of the European Group on Graves' Orbitopathy (EUGOGO) on management of GO. Eur J Endocrinol. 2008;158:273-285.

64. Wichers M, Benz E, Palmedo H, Biersack HJ, Grünwald F, Klingmüller D. Testicular function after radioiodine therapy for thyroid carcinoma. Eur J Nucl Med. 2000;27:503-507.

65. Rosário PW, Barroso AL, Rezende LL, et al. Testicular function after radioiodine therapy in patients with thyroid cancer. Thyroid. 2006;16:667-670.

66. Clement SC, Peeters RP, Ronckers CM, et al. Intermediate and long-term adverse effects of radioiodine therapy for differentiated thyroid carcinoma: a systematic review. Cancer Treat Rev. 2015;41:925-934.

67. Evranos B, Faki S, Polat SB, Bestepe N, Ersoy R, Cakir B. Effects of radioactive iodine therapy on ovarian reserve: a prospective pilot study. Thyroid. 2018;28: 1702-1707.

68. Nies M, Cantineau AEP, Arts EGJM, et al. Long-term effects of radioiodine treatment on female fertility in survivors of childhood differentiated thyroid carcinoma. Thyroid. 2020;30:1169-1176.

69. de Vathaire F, Schlumberger M, Delisle MJ, et al. Leukaemias and cancers following iodine-131 administration for thyroid cancer. Br J Cancer. 1997;75: 734-739.

70. Lang BH, Wong IO, Wong KP, Cowling BJ, Wan KY. Risk of second primary malignancy in differentiated thyroid carcinoma treated with radioactive iodine therapy. Surgery. 2012;151:844-850.

71. Silva-Vieira M, Carrilho Vaz S, Esteves S, et al. Second primary cancer in patients with differentiated thyroid cancer: does radioiodine play a role? Thyroid. 2017;27:1068-1076.

72. Verkooijen RB, Smit JW, Romijn JA, Stokkel M. The incidence of second primary tumors in thyroid cancer patients is increased, but not related to treatment of thyroid cancer. Eur J Endocrinol. 2006;155:801-806.

73. Subramanian S, Goldstein DP, Parlea L, et al. Second primary malignancy risk in thyroid cancer survivors: a systematic review and meta-analysis. Thyroid. 2007;17: 1277-1288.

74. Kitahara CM, Berrington de Gonzalez A, Bouville A, et al. Association of radioactive iodine treatment with cancer mortality in patients with hyperthyroidism. JAMA Intern Med. 2019;179:1034-1042.

75. Struja T, Schuetz P. Use of radioactive iodine treatment in patients with hyperthyroidism? A case for shared decision making. Eur J Nucl Med Mol Imaging. 2019;46:2407.

76. Giovanella L, Verburg FA. Use of radioactive iodine treatment in patients with hyperthyroidism: a case for shared decision making. Eur J Nucl Med Mol Imaging. 2019;46:2408-2409.

77. Zhang X, Shan G, Liu Q, Lin Y. Regarding the manuscript entitled "Association of radioactive iodine treatment with cancer mortality in patients with hyperthyroidism." Eur J Nucl Med Mol Imaging. 2019;46:2410-2411.

78. Taylor PN, Okosieme EO, Chatterjee K, Boelaert K. Joint statement from the Society for Endocrinology and the British Thyroid Association regarding "association of radioactive iodine treatment with cancer mortality in patients with hyperthyroidism." Clin Endocrinol (Oxf). 2020;92:266-267.

79. Giovanella L, Verburg FA, Ovčariček PP, et al. "Quid autem vides festucam in oculo fratris tui et trabemin oculo tuo non vide" on the hyperthyroidism-induced mortality and antithyroid drug-induced side effects in the era of radioiodine fake news. Eur J Nucl Med Mol Imaging. 2020;47:1342-1344.

80. Bartalena L, Burch HB, Burman KD, Kahaly GJA. 2013 European survey of clinical practice patterns in the management of Graves' disease. Clin Endocrinol (Oxf). 2016;84:115-120. 